\title{
Visible Light Catalytic Degradation of Dye Wastewater using Carbon Nitride
}

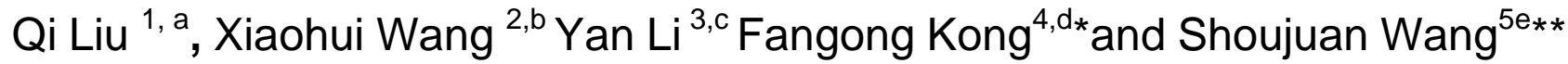 \\ Key Lab of Pulp and Paper Science \& Technology, Ministry of Education, Qilu university of \\ Technology, Ji'nan, Shandong, 250353,People's Republic of China

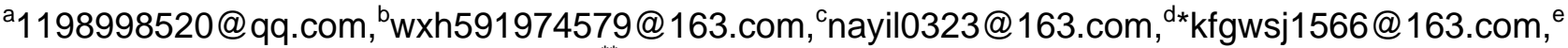 \\ nancy5921@163.com
}

Keywords: photocatalysis, graphitic carbon nitride, visible light, organic dye

Abstract. Graphite phase carbon nitride $\left(\mathrm{g}-\mathrm{C}_{3} \mathrm{~N}_{4}\right)$ as a novel semiconductor photocatalysts attracted widespread attention in recent years. In this paper, the lamellar $\mathrm{g}-\mathrm{C}_{3} \mathrm{~N}_{4}$ nano-materials prepared from solid urea was used as a photocatalyst to degrade the simulated dye wastewater under visible light irradation. In addition, the photocatalytic degradation performances of $\mathrm{g}-\mathrm{C}_{3} \mathrm{~N}_{4}$ material prepared from conventional and mechanical-conventional methods for degrading organic dye solutions were compared and discussed in detail. The Rhodamine B (RhB), Methylene Blue (MB) and Methyl Orange ( $\mathrm{MO})$ water solutions were chosen as simulated dye wastewater. The results showed that these two kinds of $\mathrm{C}_{3} \mathrm{~N}_{4}$ photocatalyst both has a high decoloration efficiency for these three dyes using visible light. Compared with that from conventional method, the $\mathrm{g}_{-} \mathrm{C}_{3} \mathrm{~N}_{4}$ from mechanical-conventional method has a higher photocatalytic performance, which offered a new process for preparing graphite phase carbon nitride. The molecule structure of dye has an effect on the visible-light decoloration efficiency of $\mathrm{g}-\mathrm{C}_{3} \mathrm{~N}_{4}$. Also, the absorption capability of dye molecules on catalyst gave an important role during this visible-light irradation process.

\section{Introduction}

Environment pollution and energy crisis are two of the most serious problems which are facing humanity today. The photocatalytic technology provides a brand new and promising solution for environmental issues. Therefore, it attracts worldwide attention due to it can absorb solar light to decompose the environmental pollutants. However, the practical application of traditional photocatalysts (such as $\mathrm{TiO}_{2}$ ) is severely limited due to their low utilization rate of solar light and poor quantum yield ${ }^{[1]}$. Therefore, exploration of high efficient photocatalysts with large specific surface area and high quantum yield becomes one of the important aims for semiconductor photocatalytic technology. The novel organic polymer semiconductor photocatalyst, graphite carbon nitride $\left(\mathrm{g}-\mathrm{C}_{3} \mathrm{~N}_{4}\right)$, has drawn much attention for its unique properties such as visible light respond, high chemical and thermal stability, environmental compatibility and economical capability. However, the photocatalytic activity of $\mathrm{g}-\mathrm{C}_{3} \mathrm{~N}_{4}$ is low due to its small specific surface area and low quantum yield. In this paper, we mainly focus on the improvement of the photocatalytic activity of g- $\mathrm{C}_{3} \mathrm{~N}_{4}$ by using mechanical treatment for enlarging its surface area.

In this paper, the prepared $\mathrm{g}-\mathrm{C}_{3} \mathrm{~N}_{4} \mathrm{~S}$ using conventional method and mechanical-conventional method were used to photocatalytically degrade the organic dyes Rhodamine $B(\mathrm{RhB})$, Methylene Blue (MB) and Methyl Orange (MO) under visible light conditions. The degradation performance of the prepared $\mathrm{g}-\mathrm{C}_{3} \mathrm{~N}_{4}$ for the dye solutions was compared and discussed detailly.

\section{Expermental}

Materials. Urea (analytical grade, solid powder, $99.5 \%$ ) was purchased from Sigma Chemicals Company. Rhodamine B, Methyl orange and Methylene Blue were supplied by Jinan Dye Company. All the chemicals were used without purification. 


\section{Methods.}

\section{Preparation of $\mathrm{g}-\mathrm{C}_{3} \mathrm{~N}_{4}$ Catalyst}

The $\mathrm{g}-\mathrm{C}_{3} \mathrm{~N}_{4}$ was prepared in this paper using two different methods. One is conventional method. The other one is mechanical-conventional method. For the conventional method, the urea powder was directly put into a ceramic crucible firstly, and then the crucible was placed into a muffle furnace and heated to $400{ }^{\circ} \mathrm{C}$, and then calcined at this temperature for $1 \mathrm{~h}$. After that, the sample was cooled to room temperature by itself in muffle furnace. When the temperature was decreased to room temperature, the ceramic crucible containing sample in the muffle furnace was again heated and make its temperature increase to $450{ }^{\circ} \mathrm{C}$ uniformly, and held at $450{ }^{\circ} \mathrm{C}$ for 2 hours. Throught this calcination, the powder in ceramic crucible was considered as the conventional $g-\mathrm{C}_{3} \mathrm{~N}_{4}$. The preparation of mechanical-conventional $\mathrm{g}_{-} \mathrm{C}_{3} \mathrm{~N}_{4}$ using the same procedure as that of conventional g- $\mathrm{C}_{3} \mathrm{~N}_{4}$ preparation. The only difference is that the urea was firstly grinded to pass the 500 mesh screen and then put the grinded powder in the ceramic crucible to follow the procedure which was used for preparing conventional $\mathrm{g}-\mathrm{C}_{3} \mathrm{~N}_{4}$.

\section{$\mathrm{X}$-ray diffraction (XRD) analysis}

The D8-ADVANCE XRD analyzer was used to record the spectrum of carbon nitride prepared in this paper. The test conditions were $\lambda=1.5442 \mathrm{~nm}, 40 \mathrm{~mA}, 40 \mathrm{KV}$, scan speed $1.8^{\circ} \mathrm{min}^{-1}$, scan range $2 \theta=5 \sim 90^{\circ}$.

\section{Photocatalytic degradation of simulated dye wastewater}

Weighed amount of catalyst was put into the simulated dye wastewater solution (dye concentration, $5 \mathrm{mg} / \mathrm{L}$ ) firstly and then the solution was mixed at $200 \mathrm{rpm}$ for $1 \mathrm{~min}$ using stirer. After that, the beaker containing the dye solution and carbon nitride catalyst was put in a dark place and ultrasounded $30 \mathrm{~min}$. The ultrasounded solution was then put into the photocatalytic reactor which equipped with visible light source which gives light with wavelength higer than $420 \mathrm{~nm}$. After certain time of reaction, part of the dye solution was taken out of the beaker and centrifugated 10 min at $12000 \mathrm{rpm}$. The supernatant was used to measure the dye concentration in the solution based on the absorbance value at the characteristic wavelength of each dye using UV-visible spectrophometer (8435 UV-Visible Spectrophotometer from Agilent Technologies) and calculate the decoloration ratio using the following equation.

decoloration ratto $\%=\left(1-\frac{c}{C_{0}}\right) \times 100$

C-dye concentration after photocatalytic degradation, $\mathrm{mg} / \mathrm{L} ; \mathrm{C}_{0^{-}}$initial dye concentration, $\mathrm{mg} / \mathrm{L}$

\section{Results and discussion}

XRD analysis. The XRD spctra of conventional $\mathrm{C}_{3} \mathrm{~N}_{4}$ and mechanical-conventional $\mathrm{C}_{3} \mathrm{~N}_{4}$ were recorded using D8-ADVANCE XRD analyzer and the spctrum of mechanical-conventional $\mathrm{C}_{3} \mathrm{~N}_{4}$ was presented in Figure 1. The spectrum of conventional $\mathrm{C}_{3} \mathrm{~N}_{4}$ has the similar characteristic peak as that of mechanical-conventional $\mathrm{C}_{3} \mathrm{~N}_{4}$. Figure 1 showed that there was two characteristic peaks in the spectrum, at $27.5^{\circ}$ and $13.1^{\circ}$ respectively. In addition, a wide adsorbance peak appeared in the range of $25 \sim 30^{\circ}$, which corresponded to the 002 crystal plane of carbon ${ }^{[2]}$. According to the Bragg equation, the interlamellar spacing is $0.33 \mathrm{~nm}$, illustrating that the sample has graphite-type structure. The peak appeared at around 13.1 o corresponded to the 100 crystal plane of carbon, illustrating the sample has the structure of Tri-s-triazine $\left(\mathrm{C}_{6} \mathrm{~N}_{7}\right)$ structure $^{[3]}$. 


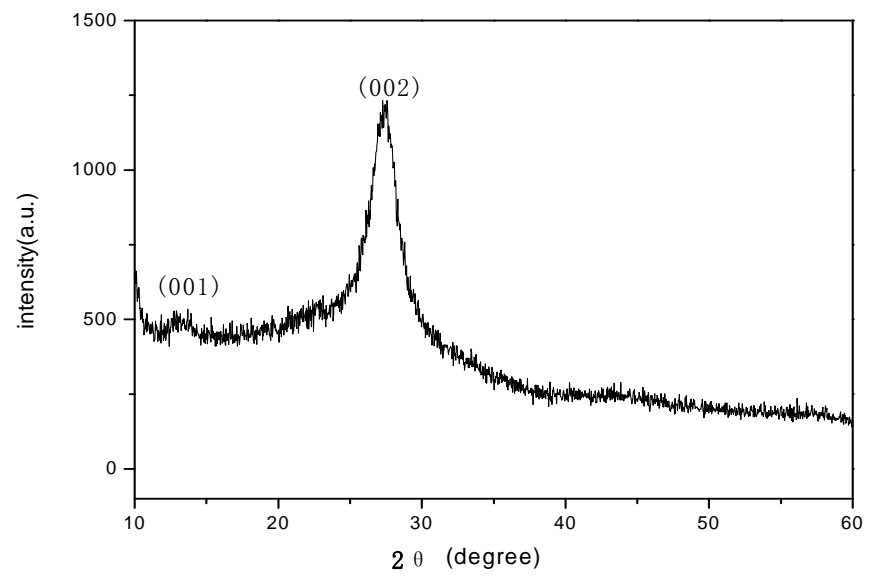

Fig. 1 The XRD pattern of the sample

\section{Photocatalytic performance of $g-\mathrm{C}_{3} \mathrm{~N}_{4}$ for simulated dye solutions.}

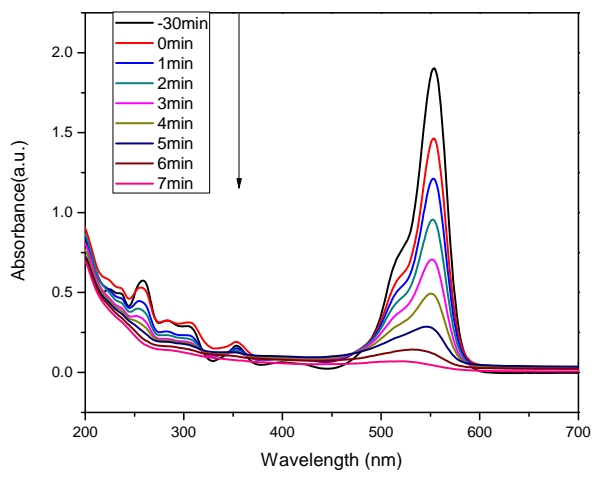

Fig.2 RhB degradation of UV-visible spectra of $\mathrm{RhB}$ using conventional g- $\mathrm{C}_{3} \mathrm{~N}_{4}$

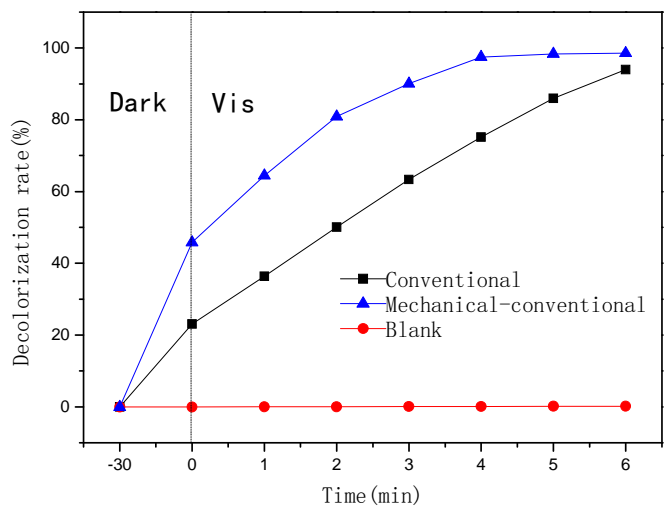

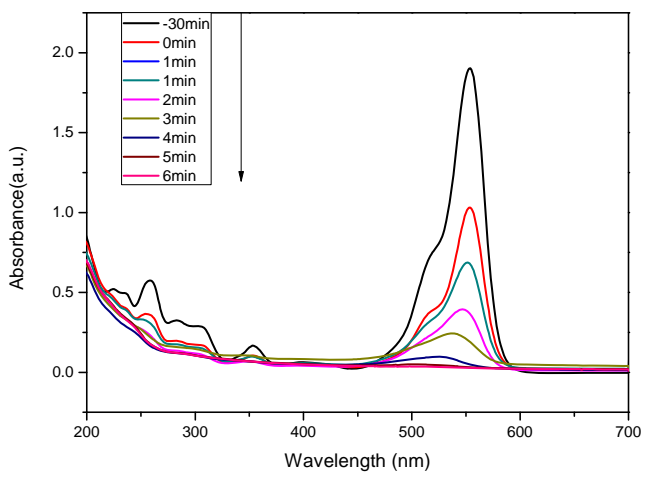

Fig.3 RhB degradation of UV-visible spectra of $\mathrm{RhB}$ using mechanical-conventional $\mathrm{g}-\mathrm{C}_{3} \mathrm{~N}_{4}$

Fig.4 RhB decolorization at different time using conventional and mechanical-conventioanl $\mathrm{g}-\mathrm{C}_{2} \mathrm{~N}_{1}$

The UV-visible spcetra of RhB dye solution during degradation using conventional $\mathrm{g}-\mathrm{C}_{3} \mathrm{~N}_{4}$ and mechnical-conventional $\mathrm{g}-\mathrm{C}_{3} \mathrm{~N}_{4}$ as photocatalytic material were presented in Figure 2 and 3. As shown in Figure 2 and Figure 3, the absorbance of characteristic peak of $\mathrm{RhB}$ dye solution decreased gradually with the increase of treatment time no matter the $\mathrm{g}-\mathrm{C}_{3} \mathrm{~N}_{4}$ is prepared from conventional method or mechanical-conventional method, illustrating that these two $\mathrm{g}_{-} \mathrm{C}_{3} \mathrm{~N}_{4}$ both have the photocatalytic capability to degrade the $\mathrm{RhB}$ dye. For the conventional $\mathrm{g}-\mathrm{C}_{3} \mathrm{~N}_{4}$, the decoloration ratio reached $97.8 \%$ when the treatment time reached 7 min. However, the decoloration ratio reached $98.3 \%$ at treatment time 5 min when using mechanical-conventional 
g- $\mathrm{C}_{3} \mathrm{~N}_{4}$, which is higher than that of conventional g- $\mathrm{C}_{3} \mathrm{~N}_{4}$. As shown, through simulation of visible light catalytic degradation, the intensity of the absorption peak of $\mathrm{RhB}$ dye solution gradually becomes smaller, while the pink color of the dye solution gradually faded. According to the literatures, this process is a gradual removal of the ethyl groups and the opening of ring structure in the RhB molecules ${ }^{[4]}$.

Figures 4 presented the decoloration ratio of $\mathrm{RhB}$ dye solution during photocatalytic degradation. As shown in Figure 4, during the dark ultrasonic treatment, before the photocatalytic reaction, the decoloration ratio of mechanical-conventional $\mathrm{g}-\mathrm{C}_{3} \mathrm{~N}_{4}, 45 \%$, is much higher than that of conventional $\mathrm{g}-\mathrm{C}_{3} \mathrm{~N}_{4}, 23 \%$, which illustrated the mechanical-conventional g- $\mathrm{C}_{3} \mathrm{~N}_{4}$ has a higher adsorption capability than the conventional $\mathrm{g}-\mathrm{C}_{3} \mathrm{~N}_{4}$ for $\mathrm{RhB}$ dye, resulted in the higher photocatalytic capability for $\mathrm{RhB}$ dye solution. When the photocatalytic time is $4 \mathrm{~min}$, the decoloration ratio of the dye solution reached $96.5 \%$ for using mechanical-conventional $\mathrm{g}-\mathrm{C}_{3} \mathrm{~N}_{4}$, however, it is only $79.5 \%$ for using conventional $\mathrm{g}-\mathrm{C}_{3} \mathrm{~N}_{4}$, which is $17 \%$ lower. Also, Figure 4 presented that the $\mathrm{RhB}$ dye can be easily decolorized or decomposed when using the prepared $\mathrm{g}-\mathrm{C}_{3} \mathrm{~N}_{4}$ as a photocatalytic material under visible light irradation.

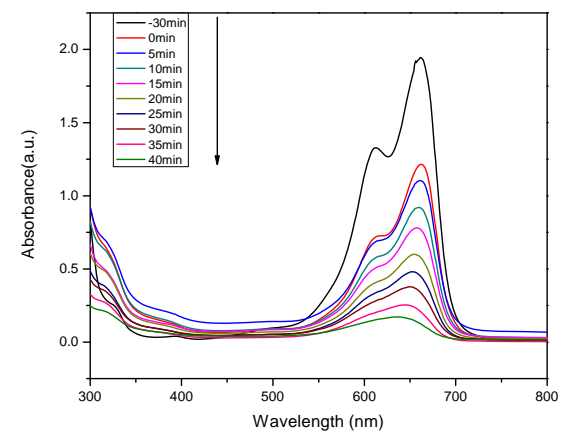

Fig.5 UV-visible spectra of MB dye solution using conventional $\mathrm{g}-\mathrm{C}_{3} \mathrm{~N}_{4}$

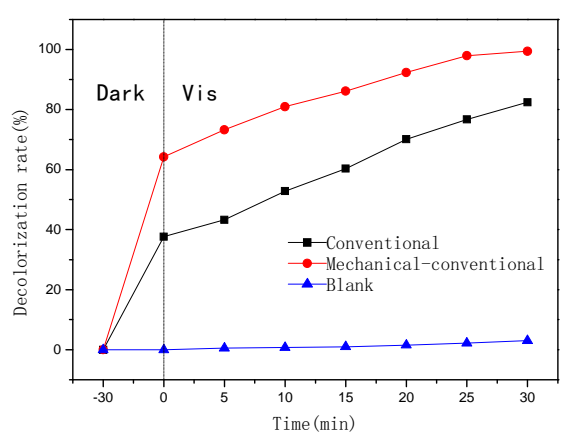

Fig.6 MB decolorization at different time using conventional and mechanical-conventioanl $\mathrm{g}-\mathrm{C}_{3} \mathrm{~N}_{4}$

Absorbance peak at characteristic wavelength dedreased gradually with the prolonging of irradation time. The decoloration ratios of $\mathrm{MB}$ dye solution using conventional and mechanical-conventional $\mathrm{g}-\mathrm{C}_{3} \mathrm{~N}_{4}$ as visible light catalyst were presented in Figure 6. Figure 6 presented that the dye concentration in the solution decreased a lot after the dark ultrasound treatment, demonstrating that the prepared $\mathrm{g}-\mathrm{C}_{3} \mathrm{~N}_{4}$ has a stronger absorption for $\mathrm{MB}$ dye than that of $\mathrm{RhB}$ dye. Also, the mechanical-conventional g- $\mathrm{C}_{3} \mathrm{~N}_{4}$ has a higher absorption capability than the conventional g- $\mathrm{C}_{3} \mathrm{~N}_{4}$, as shown in Figure 6. Compared with conventional g- $\mathrm{C}_{3} \mathrm{~N}_{4}$, the mechanical-conventional g- $\mathrm{C}_{3} \mathrm{~N}_{4}$ gives a higher catalytic performance for $\mathrm{MB}$ dye solution. When the treatment time was $30 \mathrm{~min}$, the decoloration ratio reached $99 \%$ for mechanical-conventional $\mathrm{g}-\mathrm{C}_{3} \mathrm{~N}_{4}$, which is much higher than that of the conventional $\mathrm{g}_{-} \mathrm{C}_{3} \mathrm{~N}_{4}, 82 \%$. As known, during the process of light photocatalytic degradation of organic pollutants, the catalyst can generate hydroxyl radicals $(\bullet \mathrm{OH})$ and at the same time form electron holes $\left(\mathrm{H}^{+}\right)$in the catalyst under the light irradation, which can further form superoxide radical $\left(\bullet \mathrm{O}^{2-}\right)$ and hydroxyl radical $(\bullet \mathrm{OH})$ to oxidize and degrade the pollutants ${ }^{[5,6,7]}$. 


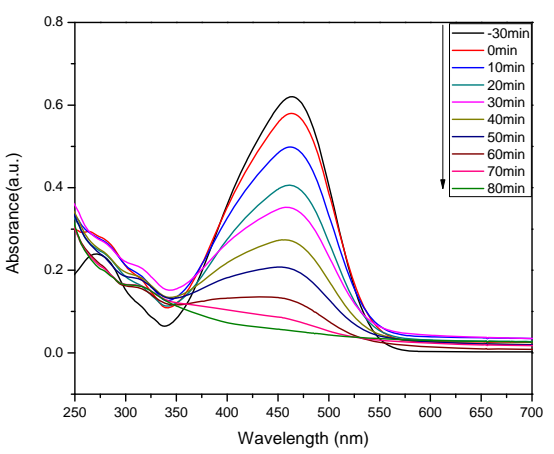

Fig.7 UV-visible spectra of $\mathrm{MO}$ dye solution using conventional $\mathrm{g}-\mathrm{C}_{3} \mathrm{~N}_{4}$

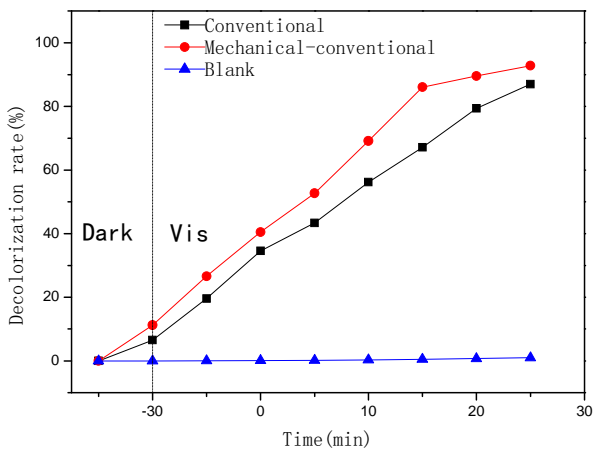

Fig.8 MO decolorization at different time using conventional and mechanical-conventioanl $\mathrm{g}-\mathrm{C}_{3} \mathrm{~N}_{4}$

The change of UV-Visible spectra of MO dye solution during photocatalytic irradation was shown in Figure 7. It can be seen that the absorbance peak at characteristic wavelength dedreased gradually with the prolonging of irradation time. During this process, the orange color of the MO dye solution faded. The decoloration ratios of MO dye solution using conventional and mechanical-conventional g- $\mathrm{C}_{3} \mathrm{~N}_{4}$ as visible light catalyst were presented in Figure 8 . Figure 8 showed that the dye concentration in the solution decreased a bit after the dark ultrasound treatment, only around $10 \%$ which is much lower than that of $\mathrm{MB}$ and $\mathrm{RhB}$ dye solution, demonstrating that the prepared $\mathrm{g}-\mathrm{C}_{3} \mathrm{~N}_{4}$ has a weak absorption for $\mathrm{MO}$ dye than that of $\mathrm{MB}$ and $\mathrm{RhB}$ dye. Also, the mechanical-conventional g- $\mathrm{C}_{3} \mathrm{~N}_{4}$ has a little higher absorption capability than the conventional $\mathrm{g}-\mathrm{C}_{3} \mathrm{~N}_{4}$, as shown in Figure 8 . Compared with conventional g- $\mathrm{C}_{3} \mathrm{~N}_{4}$, the mechanical-conventional g- $\mathrm{C}_{3} \mathrm{~N}_{4}$ gives a higher catalytic performance for $\mathrm{MO}$ dye solution. When the treatment time was $70 \mathrm{~min}$, the decoloration ratio reached $93 \%$ for mechanical-conventional $\mathrm{g}-\mathrm{C}_{3} \mathrm{~N}_{4}$, which is higher than that of the conventional $\mathrm{g}-\mathrm{C}_{3} \mathrm{~N}_{4}, 86 \%$.

Compared the decoloration ratio of these three dyes ( $\mathrm{RhB}, \mathrm{MB}$ and $\mathrm{MO})$ using conventional and mechanical-conventional g- $\mathrm{C}_{3} \mathrm{~N}_{4}$ as visible light catalyst, it can be found that these two $\mathrm{g}-\mathrm{C}_{3} \mathrm{~N}_{4}$ has different decoloration efficiency based on the dye structure. Also, the absorption capability of dye molecules on catalyst gave an important role during this visible-light irradation process.

\section{Summary}

The graphite carbon nitride, $\mathrm{g}-\mathrm{C}_{3} \mathrm{~N}_{4}$, was prepared sucessfully using solid urea through the conventional method and the mechanical-conventional method. Both the conventional $g-\mathrm{C}_{3} \mathrm{~N}_{4}$ and mechanical-conventional $\mathrm{g}-\mathrm{C}_{3} \mathrm{~N}_{4}$ can be used to decolorize the dye solution. Under the visible light irradation, the $\mathrm{g}-\mathrm{C}_{3} \mathrm{~N}_{4} \mathrm{~S}$ gave a good decoloration ratio. The decoloration ratio reached higher than $85 \%$ for using conventional $\mathrm{g}-\mathrm{C}_{3} \mathrm{~N}_{4}, 95 \%$ for using mechanical-conventional $\mathrm{g}-\mathrm{C}_{3} \mathrm{~N}_{4}$. The molecule structure of dye has an effect on the visible-light decoloration efficiency of $g-\mathrm{C}_{3} \mathrm{~N}_{4}$. Also, the absorption capability of dye molecules on catalyst gave an important role during this visible-light irradation process.

\section{Acknowledgements}

The authors are grateful for the National Natural Science Foundation of China (Grant No.31170547, 31500489, 31570566), the Key Laboratory of Pulp \& Paper Engineering of Jiangsu Province, China (No.201030), the Natural Science Foundation of Shandong (ZR2011CM011, ZR2013CQ020, 2012GSF11710) and Taishan Scholar of Shandong for their financial support to this project. 


\section{References}

[1] J. Shang, W.Yao, Y.F. Zhu, et al.,Appl. Catal. A: General, 2004, 257(1):25-32

[2] Q.Liu, J.Zhang.Langmuir, 2013, 29(11): 3821-3828.

[3] J.Zhang,X.Chen, K.Takanabe, et al. Angewandte Chemie International Edition, 2010, 49(2): 441-444.

[4] J. D. Zhuang, W. X. Dai, P. Liu. Langmuir, 2010, 26(12): 9686-9694.

[5] N.Serpone,A.V. Emeline. Res. Chem. Intermed., 2005, 31(4-6): 391-432.

[6] S.S. Soni, M.J.Henderson, J. F.Bardeau, et al. Adv. Mater., 2008, 20(8): 1493-1498.

[7] X. Wang, S. Blechert, M. Antonietti. ACS Catal. , 2012, 2:1596. 